\title{
COMMENTARY
}

\section{Think (Gram) negative!}

\author{
Benedikt Huttner and Stephan Harbarth* \\ See related research by Meyer et al., http://ccforum.com/content/14/3/R113
}

\begin{abstract}
The increasing prevalence of multiresistant Gramnegative bacteria of the Enterobacteriaceae family in Europe is a worrisome phenomenon. Extendedspectrum betalactamase-producing Escherichia coli strains are widespread in the community and are frequently imported into the hospital. Of even more concern is the spread of carbapenem-resistant strains of Klebsiella spp. from regions where they are already endemic. Antibiotic use is a main driver of antibiotic resistance, which again increases broad spectrum antibiotic use, resulting in a vicious circle that is difficult to interrupt. The present commentary highlights important findings of a surveillance study of antimicrobial use and resistance in German ICUs over 8 years with a focus on Gram-negative resistance.
\end{abstract}

In a recent issue of Critical Care, Meyer and colleagues [1] report interesting surveillance data from ICUs in 30 German hospitals, based on a large amount of microbiology and pharmacy data gathered between 2001 and 2008. One of the main study findings is a decreasing rate of methicillin-resistant Staphylococcus aureus (MRSA) and a dramatic increase of third generation cephalosporin (3GC) resistant Enterobacteriaceae over the study period. In recent years, most European countries have succeeded in reducing the burden of disease caused by MRSA [2,3].This progress has, however, been partly offset by the increase across Europe in the prevalence of multiresistant Gram-negative pathogens producing extended-spectrum betalactamases (ESBLs) or carbapenemases [4].

The current study confirms this worrisome finding and also shows an increase in carbapenem, 3GC and fluoroquinolone use in German ICUs with a stable volume of overall antibiotic use. The latter two antibiotic classes have been repeatedly identified as risk factors for carriage

${ }^{*}$ Correspondence: stephan.harbarth@hcuge.ch

Infection Control Program, University of Geneva Hospitals and Medical School, $\mathrm{CH}-1211$ Geneva 14, Switzerland of multidrug resistant Gram-negatives [5,6]. Carbapenems on the other hand are first-line drugs for the treatment of infections due to ESBL-producing bacteria. It is tempting to assume that overuse of fluoroquinolones and $3 \mathrm{GC}$ antibiotics contributed to the observed increase in ESBL producers, which subsequently increased carbapenem use.

The ecological nature of the data, however, makes it difficult to infer clear cause-and-effect relationships [7], as does the failure to differentiate between hospital- and community-acquired isolates and clinical versus surveillance cultures [8]. In addition, the analysis of trends is hampered by variation in the number of participating ICUs over time. Nevertheless, the increased burden of multidrug-resistant Gram-negative bacteria is a real phenomenon.

In contrast to MRSA, ESBL producers - notably strains of Escherichia coli carrying plasmids of the CTX-M family - are mostly imported from the community into the hospital. Assuming a relationship with antibiotic use in animals and subsequent transmission of antibiotic resistant E. coli via the food chain is alluring, but strong epidemiological evidence is still lacking $[9,10]$. Transmission of ESBL-producing organisms within families might also contribute to the spread [11]. The recently started European Union-funded SATURN project (Impact of Specific Antibiotic Therapies on the prevalence of hUman host ResistaNt bacteria) will gather more information on these risk factors.

As mentioned above, antibiotic overuse in humans probably plays a central role in the spread of ESBL producers. In the context of this study it is noteworthy that Germany has a relatively high level of fluoroquinolone use in the community [12]. As to antibiotic use in hospitals, the overall quantity of antibiotic use in German ICUs is comparable to that of other countries [13]. What about the quality of antibiotic prescribing? Although there is important heterogeneity between ICUs, inappropriate antibiotic use is still common in Germany (as in many other countries), where infectious diseases as a stand-alone speciality and antibiotic stewardship programmes are still underdeveloped [14].

Compared to other European countries or highly publicised health threats, such as bioterrorism and swine 
flu, public awareness and political commitment to control multidrug-resistant microorganisms has been slow to rise in Germany. Only recently (2009) has a German reference centre for surveillance of Gramnegative bacteria been established [15], which focuses, among other things, on detection of carbapenemaseproducing bacteria. A first outbreak of carbapenemaseproducing Klebsiella pneumoniae in Germany has recently been reported, probably linked to an index patient with previous healthcare contact in Greece [16]. The fact that two ICUs in 2008 reported carbapenemresistant $K$. pneumoniae in the current study raises the concern that these strains might already be more common in Central Europe than previously assumed since detection of these strains may be difficult with routine laboratory techniques [17].

How can we control the rise of multidrug-resistant Gram-negatives? With regard to ESBL-producers the growing community reservoir makes it unlikely that we will be able to control the spread by conventional measures targeted at nosocomial infection control. The promotion of prudent antibiotic use in the community and animal husbandry should therefore be a key priority. As to carbapenemase-producing Enterobacteriaceae, early identification of these strains and aggressive infection control measures seem essential [18]. Examining novel decolonization strategies for Gram-negative Enterobacteriacae might be a further strategy worth evaluating. If we manage to enforce all these measures, we will hopefully be able to think positive again - even with regard to Gram-negatives.

\section{Abbreviations}

$3 G C=$ third generation cephalosporin; $E S B L=$ extended-spectrum betalactamase; MRSA = methicillin-resistant Staphylococcus aureus.

\section{Competing interests}

$\mathrm{SH}$ has received consulting fees from DaVolterra (France). BH declares that he has no competing interests.

\section{Acknowledgements}

Preparation of this commentary was supported in part by the 6th and 7th Framework Programme of the European Community in the context of the projects 'Changing Behaviour of Health Care Professionals and the General Public Towards a More Prudent Use of Anti-microbial Agents' (CHAMP, contract SP5A-CT-2007-044317) and 'Impact of Specific Antibiotic Therapies on the prevalence of hUman host ResistaNt bacteria' (acronym SATURN, agreement FP7-HEALTH-2009-N²41796).

Published: 25 June 2010

\section{References}

1. Meyer E, Schwab F, Schoeren-Boersch B, Gastmeier P: Dramatic increase of third-generation cephalosporin resistant $E$. coli in German intensive care units: secular trends in antibiotic drug use and bacterial resistance, 2001-2008. Crit Care 2010, 14:R113.
2. Jarlier V, Trystram D, Brun-Buisson C, Fournier S, Carbonne A, Marty L, Andremont A, Arlet G, Buu-Hoi A, Carlet J , Decré D, Gottot S, Gutmann L, Joly-Guillou ML, Legrand P, Nicolas-Chanoine MH, Soussy CJ, Wolf M, Lucet JC, Aggoune M, Brücker G, Régnier B; Collégiale de Bactériologie-VirologieHygiène des Hôpitaux Universitaires de I'lle de France: Curbing methicillinresistant Staphylococcus aureus in 38 French hospitals through a 15-year institutional control program. Arch Intern Med 2010, 170:552-559.

3. Liebowitz LD: MRSA burden and interventions. Int J Antimicrob Agents 2009, 34 Suppl 3:S11-13.

4. Coque TM, Baquero F, Canton R: Increasing prevalence of ESBL-producing Enterobacteriaceae in Europe. Euro Surveill 2008, 13:19044.

5. Rodríguez-Baño J, Picón E, Gijón P, Hernández JR, Ruíz M, Peña C, Almela M, Almirante B, Grill F, Colomina J, Giménez M, Oliver A, Horcajada JP, Navarro G, Coloma A, Pascual A; Spanish Network for Research in Infectious Diseases (REIPI): Community-onset bacteremia due to extended-spectrum betalactamase-producing Escherichia coli: risk factors and prognosis. Clin Infect Dis 2010, 50:40-48.

6. Gasink LB, Edelstein PH, Lautenbach E, Synnestvedt M, Fishman NO: Risk factors and clinical impact of Klebsiella pneumoniae carbapenemaseproducing K. pneumoniae. Infect Control Hosp Epidemiol 2009, 30:1180-1185.

7. Harbarth S, Harris AD, Carmeli Y, Samore MH: Parallel analysis of individual and aggregated data on antibiotic exposure and resistance in gramnegative bacilli. Clin Infect Dis 2001, 33:1462-1468.

8. Harbarth S, Pittet D: Multiresistance of gram-negative bacteria in intensive care units: bad news from without. Crit Care Med 1999, 27:1037-1038.

9. Hammerum AM, Heuer OE: Human health hazards from antimicrobialresistant Escherichia coli of animal origin. Clin Infect Dis 2009, 48:916-921.

10. Jakobsen L, Kurbasic A, Skjøt-Rasmussen L, Ejrnaes K, Porsbo L, Pedersen K, Jensen LB, Emborg HD, Agersø Y, Olsen KE, Aarestrup FM, Frimodt-Møller N, Hammerum AM: Escherichia coli isolates from broiler chicken meat, broiler chickens, pork, and pigs share phylogroups and antimicrobial resistance with community-dwelling humans and patients with urinary tract infection. Foodborne Pathog Dis 2010, 7:537-547.

11. Valverde A, Grill F, Coque TM, Pintado V, Baquero F, Canton R, Cobo J: High rate of intestinal colonization with extended-spectrum-beta-lactamaseproducing organisms in household contacts of infected community patients. J Clin Microbiol 2008, 46:2796-2799.

12. Muller A, Coenen S, Monnet DL, Goossens H: European Surveillance of Antimicrobial Consumption (ESAC): outpatient antibiotic use in Europe, 1998-2005. Euro Surveill 2007, 12:E071011 071011.

13. Hanberger H, Arman D, Gill H, Jindrák V, Kalenic S, Kurcz A, Licker M, Naaber P Scicluna EA, Vanis V, Walther SM: Surveillance of microbial resistance in European Intensive Care Units: a first report from the Care-ICU programme for improved infection control. Intensive Care Med 2009, 35:91-100.

14. Kern WV, Steib-Bauert M, Amann S, Fellhauer M, de With K: Hospital antibiotic management in Germany - results of the ABS maturity survey of the ABS International group. Wien Klin Wochenschr 2008, 120:294-298.

15. NRZ für gramnegative Krankenhauserreger [http://memiserf.medmikro. ruhr-uni-bochum.de/nrz/]

16. Wendt C, Schutt S, Dalpke AH, Konrad M, Mieth M, Trierweiler-Hauke B, Weigand MA, Zimmermann S, Biehler K, Jonas D: First outbreak of Klebsiella pneumoniae carbapenemase (KPC)-producing K. pneumoniae in Germany. Eur J Clin Microbiol Infect Dis 2010, 29:563-570.

17. Nordmann P, Cuzon G, Naas T: The real threat of Klebsiella pneumoniae carbapenemase-producing bacteria. Lancet Infect Dis 2009, 9:228-236.

18. Carmeli Y, Akova M, Cornaglia G, Daikos GL, Garau J, Harbarth S, Rossolini GM, Souli M, Giamarellou H: Controlling the spread of carbapenemaseproducing Gram-negatives: therapeutic approach and infection control. Clin Microbiol Infect, 16:102-111.

doi:10.1186/cc9041

Cite this article as: Huttner B, Harbarth S: Think (Gram) negative! Critical Care 2010, 14:171. 